\title{
Factors Associated with Postpartum Depressive Symptoms in Community of Central Nepal
}

\author{
Pratima Dawadi (D), Aarati Sharma Bhatta, and Jayalaxmi Shakya \\ School of Nursing, Chitwan Medical College, Bharatpur, Chitwan, Nepal \\ Correspondence should be addressed to Pratima Dawadi; pratimadawadee@gmail.com
}

Received 27 November 2019; Revised 25 February 2020; Accepted 20 March 2020; Published 6 April 2020

Academic Editor: Henrik Rasmussen

Copyright ( 2020 Pratima Dawadi et al. This is an open access article distributed under the Creative Commons Attribution License, which permits unrestricted use, distribution, and reproduction in any medium, provided the original work is properly cited.

\begin{abstract}
Background. Pregnancy and postpartum are considered as high risk periods for the emergence of psychiatric disorder. Although postpartum depressive symptoms have been associated with tragic outcome, such as maternal suicide and infanticide, it is a neglected area of mental health care in developing countries. This study was conducted to find the prevalence and factors associated with postpartum depressive symptoms. Method. A community-based cross-sectional research design was carried out after selecting the three wards of Bharatpur submetropolitan by nonprobability purposive sampling method. A total of 160 mothers in their 1 month to 12 months of postpartum period were interviewed through semistructured interview schedule and Edinburgh Postnatal Depression Scale (EPDS). Collected data were entered in Epi, data 3.1, and was exported into IBM SPSS 20 version. Results. The prevalence of depressive symptoms among postpartum mothers was $27.5 \%$. The multivariate analysis identified two factors significantly associated with postpartum depression including respondents who had education level of $\leq 10$ class (odds ratio $[\mathrm{AOR}]=3.25, P=0.03$, confidence interval $[\mathrm{CI}]=1.10-9.58$ ), chronic disease in their family (odds ratio $[\mathrm{AOR}]=3.25, P=0.01$, confidence interval $[\mathrm{CI}]=1.19-8.16$ ). Conclusion. More than one out of four mothers is suffering from depressive symptoms. The major factors associated with postpartum depressive symptoms are education of respondents and chronic disease in the family. Screening and timely management of depressive symptoms should be incorporated in routine maternal care so as to enhance maternal and child health. Likewise, concerned authority should plan and organize awareness-raising programs and provide attractive package to attract the female population for higher education.
\end{abstract}

\section{Background}

Postpartum depression (PPD) is a mood disorder to describe the various disorders such as anxiety, loss of enjoyment, sadness, and fatigue which may have serious adverse long-term effects on both the children and mothers [1]. It is common for women to experience the "baby blues" feeling stressed, sad, anxious, lonely, tired, or weepy following their baby's birth, some women, up to 1 in 7 , experience postpartum depression (PPD [2].

About 7\% of the global burden of diseases among women is attributed to mental health problems, especially among women of reproductive age. Postpartum nonpsychotic depression is the most common complication of childbearing affecting approximately $10-15 \%$ of women and as such represents a considerable public health problem affecting women and their families [3] which ultimately affects progress towards the achievement of several Sustainable Development Goals (SDGs) by 2030.

Many researchers who used the Edinburgh postnatal depression scale have been used the term post-partum depression and post-partum depressive symptoms interchangeably. The concept of depression was used widely to mean depressive symptoms, even though depression criteria are defined in Diagnostic and Statistical Manual of Mental Disorder [4]. The Edinburgh Postpartum Depression Scale has been translated from the original English version to a number of languages and has been validated and used successfully in detecting postnatal depression in many countries [5].

A meta-analysis of 59 studies from North America, Europe, Australia and Japan found an average prevalence rate of postpartum depressive symptoms of $13 \%$ [6]. Preva- 
lence rates of postpartum depressive symptoms among postpartum women in developing countries India and Nepal vary from 11 to $30 \%[7,8]$.

Postpartum depressive symptoms have been associated with tragic outcome, such as maternal suicide and infanticide; it is a neglected area of mental health care in developing countries. Hence, the aim of this study is to determine the prevalence and various factors associated with depressive symptoms among postpartum mothers.

\section{Methods}

2.1. Study Setting. The study was conducted in three selected wards of Bharatpur metropolitan. Bharatpur is a city situated in the central-southern part of Nepal. Study population was women in their 4 weeks to 1 year of postpartum period [2].

2.2. Sampling Procedure. First of all, nonprobability purposive sampling technique was used to select the three different wards of Bharatpur submetropolitan of central Nepal from November 2017 to May 2018. Total list of postpartum mothers who met the inclusion criteria of the study was taken from the immunization record register of Shivanagar Primary Health Center (PHC). There was a record of 160 postpartum mothers and all recorded number of mothers was taken as a sample.

2.3. Research Instrument. Semistructured interview schedule was developed by researcher herself after reviewing of related literature for sociodemographic characteristic and factors associated with depressive symptoms. Researcher also used the standard tool (Edinburgh Postpartum Depression Scale) to measure the prevalence of postpartum depressive symptoms. The instruments consist of 3 parts-Part I, Part II, and Part III.

Part I: questions related to sociodemographic characteristics of postpartum mother.

Part II: questions related to postpartum depressive symptoms.

Part III: questions related to factors associated with depressive symptoms among postpartum mothers.

Content validity of the research instrument was established by using standard Edinburgh Postpartum Depression Scale (EPDS) [5]. It is validated and used in different cultural setting, including Nepal [9]. The research instrument was translated into Nepali language to make clear and easy for taking information from the respondents. Pretesting of tool was done on 16 postpartum mothers of ward number 29 of Bharatpur metropolitan and modification on tools done accordingly.

2.4. Data Analysis Procedure. The data derived from semistructured interview were coded and entered in Epi data 3.1 , and the entered data was exported into IBM SPSS 20 version. The data was analyzed and calculated according to the nature of the variable by using descriptive statistic (percentage, mean, and standard deviation) and inferential statistic (binary logistic regression and multivariate logistic regression) was used to test the association between the variables.
TABle 1: Association between depressive symptoms and sociodemographic factors among postpartum mothers.

\begin{tabular}{|c|c|c|}
\hline \multirow{2}{*}{ Sociodemographic factors } & \multicolumn{2}{|c|}{ Depressive symptoms } \\
\hline & Present no. (\%) & Absent no. (\%) \\
\hline \multicolumn{3}{|l|}{ Age } \\
\hline$<20$ & $6(30)$ & $14(70)$ \\
\hline $20-29$ & $27(23.5)$ & $88(76)$ \\
\hline$\geq 30$ & $11(44)$ & $14(56)$ \\
\hline \multicolumn{3}{|l|}{ Ethnicity } \\
\hline Bramhan/Chettri & $19(24.4)$ & $59(75.6)$ \\
\hline Others & $25(30.5)$ & $57(69.5)$ \\
\hline \multicolumn{3}{|l|}{ Religion } \\
\hline Hindu & $34(25.6)$ & $99(74.4)$ \\
\hline Others & $10(37)$ & $17(63)$ \\
\hline \multicolumn{3}{|l|}{ Type of family } \\
\hline Nuclear family & $24(34.8)$ & $45(65.2)$ \\
\hline Joint family & $20(22)$ & $71(78)$ \\
\hline \multicolumn{3}{|c|}{ Type of marriage of respondent } \\
\hline Single marriage & $42(27.3)$ & $112(72.7)$ \\
\hline Remarriage & $2(33.3)$ & $4(66.7)$ \\
\hline \multicolumn{3}{|l|}{ Husband's type of marriage } \\
\hline Single marriage & $38(26.2)$ & $107(73.8)$ \\
\hline Remarriage & $6(40)$ & $9(60)$ \\
\hline \multicolumn{3}{|c|}{ Total income per month (NRs) } \\
\hline$\leq 50000$ & $41(29.5)$ & $98(70.5)$ \\
\hline$>50000$ & $31(4.3)$ & $18(85.7)$ \\
\hline \multicolumn{3}{|c|}{ Education level of respondents } \\
\hline$\leq 10$ class & $35(32.7)$ & $72(67.3)$ \\
\hline$>10$ class & $9(17)$ & $44(83)$ \\
\hline \multicolumn{3}{|l|}{ Occupation of respondents } \\
\hline Housewife & $41(29.9)$ & $96(70.1)$ \\
\hline Other than housewife & $3(13)$ & $20(87)$ \\
\hline \multicolumn{3}{|l|}{ Education level of husbands } \\
\hline$\leq 10$ class & $35(32.7)$ & $72(67.3)$ \\
\hline$>10$ class & $9(17)$ & $44(83)$ \\
\hline \multicolumn{3}{|l|}{ Occupation of husbands } \\
\hline Foreign employment & $15(20.5)$ & $58(79.6)$ \\
\hline Service & $4(16)$ & $21(84)$ \\
\hline Others $^{\wp}$ & $25(40.3)$ & $37(59.7)$ \\
\hline
\end{tabular}

${ }^{\mathfrak{r}}$ Others' occupation (agriculture, daily wages, and others).

\section{Result}

3.1. Prevalence of Depressive Symptom among Postpartum Mothers. Out of 160 respondents, 27.5\% of respondents had postpartum depressive symptoms and $72.5 \%$ respondent did not have depressive symptoms.

3.2. Association between Depressive Symptoms and Sociodemographic Factors among Postpartum Mothers. Among the study participants, most of the depressive symptoms were observed in age group $>30$ years $(44 \%) .34 .8 \%$ of respondents with depressive symptoms were from nuclear 
TABle 2: Association between depressive symptoms and motherrelated factors among postpartum mothers.

\begin{tabular}{|c|c|c|}
\hline \multirow{2}{*}{ Mother-related factors } & \multicolumn{2}{|c|}{ Depressive symptoms } \\
\hline & Present no. (\%) & Absent no. (\%) \\
\hline \multicolumn{3}{|c|}{ Chronic disease of respondent } \\
\hline Yes & $1(33.3)$ & $2(66.7)$ \\
\hline No & $43(27.4)$ & $114(72.6)$ \\
\hline \multicolumn{3}{|l|}{ Chronic disease in family } \\
\hline Yes & $16(42.1)$ & $22(57.9)$ \\
\hline No & $28(23)$ & $94(77)$ \\
\hline \multicolumn{3}{|l|}{ Depression in respondent } \\
\hline Yes & $1(25)$ & $3(75)$ \\
\hline No & $43(27.6)$ & $113(72.4)$ \\
\hline \multicolumn{3}{|l|}{ Depression in family } \\
\hline Yes & $1(9.1)$ & $10(90.9)$ \\
\hline No & $43(28.9)$ & $106(71.1)$ \\
\hline \multicolumn{3}{|l|}{ Gravid } \\
\hline Prim & $16(22.2)$ & $56(77.8)$ \\
\hline Multi & $28(31.8)$ & $60(68.2)$ \\
\hline \multicolumn{3}{|l|}{ Abortion } \\
\hline Yes & $6(23.1)$ & $20(7.9)$ \\
\hline No & $38(28.4)$ & $96(71.6)$ \\
\hline \multicolumn{3}{|l|}{ Stillbirth ${ }^{\epsilon}$} \\
\hline Yes & $4(80)$ & $1(20)$ \\
\hline No & $40(25.8)$ & $115(74.2)$ \\
\hline \multicolumn{3}{|l|}{ Multiple pregnancy } \\
\hline Singleton & $44(27.7)$ & $115(72.3)$ \\
\hline Twins or triple & $0(0)$ & $1(100)$ \\
\hline \multicolumn{3}{|l|}{ Planned pregnancy } \\
\hline Yes & $21(27.3)$ & $56(72.7)$ \\
\hline No & $23(27.7)$ & $60(72.3)$ \\
\hline \multicolumn{3}{|c|}{ Problem during pregnancy } \\
\hline Yes & $3(30)$ & $7(70)$ \\
\hline No & $41(27.3)$ & $109(72.7)$ \\
\hline \multicolumn{3}{|l|}{ ANC visits } \\
\hline 4 visits completed & $32(24.2)$ & $100(75.8)$ \\
\hline 4 visits not completed & $12(42.9)$ & $16(57.1)$ \\
\hline \multicolumn{3}{|l|}{ Mode of delivery } \\
\hline Vaginal & $32(24.4)$ & $99(75.6)$ \\
\hline Cesarean section & $12(41.4)$ & $17(58.6)$ \\
\hline
\end{tabular}

family. $33.3 \%$ of participants with depressive symptoms were remarried. Various sociodemographic factors and association of depressive symptoms are summarized in Table 1.

3.3. Association between Depressive Symptoms and MotherRelated Factors among Postpartum Mothers. Postpartum depressive symptoms were most commonly observed among the respondents with chronic disease in family $(42.1 \%)$. In the same way, depressive symptoms were observed more (42.9\%) in those who did not complete 4 ANC visits in comparison with those who completed 4 ANC visit. $80 \%$ of participants with previous history of stillbirth had depressive
TABLE 3: Association between prevalence of depressive symptoms and husband-related factors among postpartum mothers.

\begin{tabular}{|c|c|c|}
\hline \multirow{2}{*}{ Husband-related factors } & \multicolumn{2}{|c|}{ Depressive symptoms } \\
\hline & Present no. (\%) & Absent no. (\%) \\
\hline \multicolumn{3}{|l|}{ Alcohol consumption } \\
\hline Yes & $27(37)$ & $46(63)$ \\
\hline No & $17(19.5)$ & $70(80.5)$ \\
\hline \multicolumn{3}{|l|}{ Physical violence } \\
\hline Yes & $10(33.3)$ & $20(66.7)$ \\
\hline No & $34(26.2)$ & $96(73.8)$ \\
\hline \multicolumn{3}{|l|}{ Psychological violence } \\
\hline Yes & $11(52.4)$ & $10(47.6)$ \\
\hline No & $33(23.7)$ & $106(76.3)$ \\
\hline \multicolumn{3}{|l|}{ Sexual violence } \\
\hline Yes & $8(38.1)$ & $13(61.9)$ \\
\hline No & $36(25.9)$ & $103(74.4)$ \\
\hline \multicolumn{3}{|l|}{ Recent conflict } \\
\hline Yes & $14(34.1)$ & $27(65.9)$ \\
\hline No & $30(25.2)$ & $89(74.8)$ \\
\hline \multicolumn{3}{|l|}{ Currently lives together } \\
\hline Yes & $34(32.4)$ & $71(67.6)$ \\
\hline No & $10(18.2)$ & $45(81.8)$ \\
\hline \multicolumn{3}{|l|}{ Husband support } \\
\hline Yes & $31(26.5)$ & $86(73.5)$ \\
\hline No & $13(30.2)$ & $30(69.8)$ \\
\hline
\end{tabular}

symptoms. The various mother-related factors and their association with PPD symptoms are described in Table 2.

3.4. Association between Prevalence of Depressive Symptoms and Husband-Related Factors among Postpartum Mothers. Postpartum depressive symptoms were observed in respondents whose husband consumed alcohols (37\%). Likewise, mental violence was observed in $52.4 \%$ of respondents with PPD symptoms. The association of PPD symptoms and husband-related factors is mentioned in Table 3.

3.5. Binary Logistic Regression Analysis on Prevalence of Depressive Symptoms with Selected Variables among Postpartum Mothers. The respondents whose educational level was 10 class or less were 2.78 times more likely to have depressive symptoms as compared to the respondents whose education level was $>10$ class $(\mathrm{COR}=2.78,95 \% \mathrm{CI}$ : 1.21 $6.40)$. In the same way, respondents whose husband's educational level was 10 class or less were 2.37 times more likely to have postpartum depressive symptoms $(\mathrm{COR}=2.37,95 \% \mathrm{CI}$ : 1.04-5.41). It was found that respondent's husbands who were engaged in other occupations were 2.61 times more likely to have depressive symptoms as compared to service $(\mathrm{COR}=2.61,95 \% \mathrm{CI}: 0.21-2.47)$. In the same way, respondent's husbands engaged in foreign employment were 0.73 times more likely to have depressive symptoms as compared with service $(\mathrm{COR}=0.73,95 \% \mathrm{CI}$ : 1.08-11.5).

Respondents who had chronic disease in family were 2.44 times more likely to have depressive symptoms as compared 
TABLE 4: Binary logistic regression analysis on prevalence of depressive symptoms with selected variables among postpartum mothers.

\begin{tabular}{|c|c|c|c|c|}
\hline \multirow{2}{*}{ Variables } & \multicolumn{2}{|c|}{ Depressive symptoms } & \multirow{2}{*}{ Unadjusted OR } & \multirow{2}{*}{$95 \% \mathrm{CI}$} \\
\hline & Absent no. (\%) & Present no. (\%) & & \\
\hline \multicolumn{5}{|c|}{ Respondent's education level } \\
\hline$\leq 10$ class & $51(85)$ & $9(15)$ & 2.78 & $1.21-6.40^{* *}$ \\
\hline$>10$ class & $61(76)$ & $39(33)$ & 1 & \\
\hline \multicolumn{5}{|c|}{ Education level of husband } \\
\hline$\leq 10$ class & $44(83)$ & $9(17)$ & 2.37 & $1.04-5.41^{* *}$ \\
\hline$>10$ class & $72(67.3)$ & $35(32.7)$ & 1 & \\
\hline \multicolumn{5}{|l|}{ Occupation of husband } \\
\hline Service & $21(84)$ & $4(16)$ & 1 & \\
\hline Foreign employment & $58(79.6)$ & $15(20.5)$ & 0.73 & $0.21-2.47$ \\
\hline Others $^{\wp}$ & $37(59.7)$ & $25(40.3)$ & 2.61 & $1.22-5.59^{* *}$ \\
\hline \multicolumn{5}{|l|}{ Chronic disease in family } \\
\hline Yes & $22(57.9)$ & $16(42.1)$ & 2.44 & $1.13-5.27^{* *}$ \\
\hline No & $94(77)$ & $28(23)$ & 1 & \\
\hline \multicolumn{5}{|l|}{ ANC visits } \\
\hline 4 visits completed & $100(75.8)$ & $32(24.2)$ & 1 & \\
\hline 4 visits not completed & $16(57.1)$ & $12(42.9)$ & 2.34 & $1.00-5.41^{* *}$ \\
\hline \multicolumn{5}{|l|}{ Parity } \\
\hline Primi & $65(79.3)$ & $17(20.7)$ & 1 & \\
\hline Multi & $51(65.4)$ & $27(36.4)$ & 2.02 & $0.99-4.11$ \\
\hline \multicolumn{5}{|l|}{ Stillbirth } \\
\hline Yes & $1(20)$ & $4(80)$ & 11.50 & $1.24-105.95^{*}$ \\
\hline No & $115(74.2)$ & $40(25.8)$ & 1 & \\
\hline \multicolumn{5}{|c|}{ Alcohol consumption by husband } \\
\hline Yes & $46(63)$ & $27(37)$ & 2.41 & $1.18-4.92^{* *}$ \\
\hline No & $70(80.5)$ & $17(19.5)$ & 1 & \\
\hline \multicolumn{5}{|l|}{ Psychological violence } \\
\hline Yes & $10(47.6)$ & $11(52.4)$ & 3.53 & $1.37-9.05^{* *}$ \\
\hline No & $106(76.3)$ & $33(23.7)$ & 1 & \\
\hline
\end{tabular}

${ }^{8}$ Others' occupation (agriculture, daily wages, and others). 1 = reference group, ${ }^{* *}$ significance at $95 \%$ CI.

to who did not have chronic disease in family $(\mathrm{COR}=2.44$, 95\% CI: 1.13-5.27). Respondents who had stillbirth before had 11.5 times more likely to have depressive symptoms among postpartum mothers $(\mathrm{COR}=2.44,95 \% \mathrm{CI}: 1.04-5.27)$.

The findings show that respondents who did not completed 4 ANC visits were 2.34 times more likely to have depressive symptoms than respondents who completed 4 $\mathrm{ANC}$ visit $(\mathrm{COR}=2.34,95 \% \mathrm{CI}$ : 1.004-5.47) .

The findings also showed that the respondents whose husbands drink alcohol were 2.41 times more likely to have depressive symptoms in postpartum period as compared with those respondents whose husbands never had alcohol $(\mathrm{COR}=2.41,95 \% \mathrm{CI}$ : 1.18-4.92). Similarly, those respondents who had mental violence were 3.53 times more likely to have depressive symptoms as compared to those who did not suffer from mental violence (COR $=3.53,95 \%$ CI: 1.37-9.05).

It was found that parity of respondents was not significantly associated with depressive symptoms among postpartum mothers (Table 4).
3.6. Multivariate Logistic Regression Analysis of Prevalence of Depressive Symptoms with Selected Variables among Postpartum Mothers. Respondents who had educational level of $\leq 10$ class were 3.25 times more likely to develop depressive symptoms in comparison with educational level above 10 class. In the same way, respondents who had a chronic disease in the family were 3.25 times more likely to have depressive symptoms as compared with respondents who did not have chronic disease in family.

However, other variables, education level of husband, occupation of husband, number of ANC visit, parity, alcohol consumption by husband, and mental violence were not statistically significant with depressive symptoms among postpartum mothers (Table 5).

\section{Discussion}

This community-based cross-sectional study was designed to identify the prevalence and factors associated with depressives symptoms among postpartum mothers. The prevalence 
TABLE 5: Multivariate logistic regression analysis of prevalence of depressive symptoms with selected variables among postpartum mothers.

\begin{tabular}{|c|c|c|c|}
\hline Variables & Unadjusted OR (95\% CI) & Adjusted OR (95\% CI) & $P$ value \\
\hline \multicolumn{4}{|c|}{ Respondent's educational level } \\
\hline$\leq 10$ class & $2.78(1.21-6.40)$ & $3.25(1.10-9.58)$ & $0.03^{* *}$ \\
\hline$>10$ class & 1 & 1 & \\
\hline \multicolumn{4}{|c|}{ Educational level of husband } \\
\hline$\leq 10$ years & $2.37(1.04-5.41)$ & $0.81(0.27-2.42)$ & 0.70 \\
\hline$>10$ years & 1 & 1 & \\
\hline \multicolumn{4}{|l|}{ Occupation of husband } \\
\hline Service & 1 & 1 & \\
\hline Foreign employment & $0.73(0.21-2.47)$ & $1.06(0.28-3.98)$ & 0.92 \\
\hline Others ${ }^{\mathfrak{\wp}}$ & $2.61(1.22-5.59)$ & $1.87(0.77-4.56)$ & 1.87 \\
\hline \multicolumn{4}{|c|}{ Chronic disease in family } \\
\hline Yes & $2.44(1.13-5.27)$ & $3.25(1.29-8.16)$ & $0.01^{* *}$ \\
\hline No & 1 & 1 & \\
\hline \multicolumn{4}{|l|}{ ANC visits } \\
\hline 4 visits completed & 1 & 1 & \\
\hline 4 visit not completed & $2.34(1.00-5.41)$ & $1.61(0.57-4.52)$ & 0.36 \\
\hline \multicolumn{4}{|l|}{ Parity } \\
\hline Primi & 1 & 1 & \\
\hline Multi & $2.02(0.99-4.11)$ & $1.52(0.66-3.50)$ & 0.31 \\
\hline \multicolumn{4}{|c|}{ Alcohol consumption by husband } \\
\hline Yes & $2.41(1.18-4.92)$ & $1.77(0.76-4.12)$ & 0.81 \\
\hline No & 1 & 1 & \\
\hline \multicolumn{4}{|l|}{ Psychological violence } \\
\hline Yes & $3.53(1.37-9.05)$ & $1.90(0.63-5.73)$ & 0.24 \\
\hline No & 1 & 1 & \\
\hline
\end{tabular}

'Others' occupation (agriculture, daily wages, and others). $1=$ reference group, ${ }^{* *}$ significance at $95 \%$ CI.

of depressive symptoms in this study was $27.5 \%$. This finding is consistent with the study conducted in Dhulikhel Hospital, Dhulikhel, Kavre and Maternity Hospital, Kathmandu $[8,10]$. Likewise, the study conducted in rural tertiary care hospital of Karnataka, India, reported that $31.4 \%$ mothers had postpartum depression [11] which is consistent with the finding from Brazil [12]. However, this finding is inconsistent with the study conducted in rural population of Dhanusa district, which reported that $9.8 \%$ had postpartum depression [13]. This inconsistent result might be due to the difference in the sociodemographic factors of that particular place. Most of the participants were of young reproductive age group which is commonly observed in our country Nepal [8]. Concerning the sex of last child, 56.3\% were male whereas $43.7 \%$ were females. This study is consistent with the study conducted in Vietnam [14].

The binary logistic analysis revealed depressive symptoms was 2.37 times more likely on those respondents whose husband's education level was $\leq 10$ class as compared to husband having education level of $>10$ class. Similarly, a study conducted in Lalitpur, district of Nepal, also showed similar results [15].

The study revealed that the husband of respondents who were engaged in other occupation (agriculture, daily wages and other) were 2.61 times more likely to have depressive symptoms as compared with service and foreign employment and service. This study is consistent with the study conducted in India where the respondents whose husbands were engaged in farming were more likely to develop depressive symptoms [11].

Likewise, in this study, respondents who were multiparity had a 2.02 times more likely to have depressive symptoms as compared to those respondents who were primiparity. The finding of this study is also compatible with the study conducted in rural area of Dhanusha district, Nepal [13].

Respondents whose husbands consume alcohol were 2.41 times more likely to have depressive symptoms than respondents whose husband never consume alcohol. The finding of this study is in the line with study conducted in Lalitpur Nepal [15]. Similarly, the study conducted in Morang District revealed that the drinking habit of the husband was associated with depressive symptoms among postpartum mothers [16].

Participants who suffered from mental violence were 3.53 times more likely to have depressive symptoms as compared with no mental violence. A previous study reported violence as a significant cause of depressive symptoms [15]. The finding of this study showed that the respondents who have a history of stillbirth were 11.5 times more likely to develop depressive symptoms in compare with no history of stillbirth. It is supported by the study conducted in Dhanusha [13]. 
This study revealed that the respondents who visited ANC clinic less than 4 times during their last pregnancy were 2.34 times more likely to develop depressive symptoms in postpartum period. It may be because ANC visit provides an opportunity for the pregnant women to be aware regarding difficulties that may occur during pregnancy and postpartum period. During ANC visit, pregnant women will receive medical information over maternal psychological changes in pregnancy. So, ANC visit also works as a stress-reducing method for pregnant women to reduce risk of postpartum depression. Moreover, respondent's chronic disease, previous history of depression, multiple pregnancies, planned pregnancy, problem during pregnancy, mode of delivery, sex of last child, preferred sex of last child, gestational week, physical and sexual violence by husband, staying with husband, recent conflict with husband and family, and support from husband and family were not found to be associated with depressive symptoms.

The multivariate logistic regression analysis in this study revealed that respondents who had educational level of $\leq 10$ years were 3.25 times more likely to develop depressive symptoms in comparison with educational level above 10 years. This finding is consistent with the study conducted in Lalitpur and Dhanusa of Nepal $[13,15]$.

Regarding chronic disease in the family, respondents who had a chronic disease in the family were 3.25 times more likely to have depressive symptoms in comparison with respondents who did not have chronic disease in the family. This finding is consistent with the study conducted in Oman [17] and Cameroon [18].

The limitation of this study includes the nonprobability purposive sampling technique and use of EPDS tool for the screening of depressive symptoms without any clinical diagnosis. It was cross-sectional study conducted among minimum number of postpartum women, so further analytical and interventional studies need to be conducted to find the various factors associated with postpartum depression.

\section{Conclusion}

This study was conceived to identify and understand the prevalence and factors associated with depressive symptoms among postpartum mothers. Nearly one out of four mothers is suffering from depressive symptoms. The major factors associated with postpartum depressive symptoms are education of respondents, occupation of husband, educational level of husband, alcohol taking habit of husband, chronic disease in the family, stillbirth, less than 4 antenatal visit, parity, and psychological violence.

\section{Abbreviations}

EPDS: Edinburgh Postnatal Depression Scale

PPD: Postpartum depression

ANC: Antenatal care.

\section{Data Availability}

All authors had full access to the data and materials. Data are available within this article. Detailed data is available from the authors upon reasonable request.

\section{Ethical Approval}

Ethical approval was obtained from the Institutional Review Committee of Chitwan Medical College (ref: CMC-IRC/072/073-105).

\section{Consent}

Written informed consent was obtained from all the participants prior to their enrollment in the study.

\section{Conflicts of Interest}

All authors declare that they have no conflict of interest.

\section{Authors' Contributions}

PD was the principal investigator as well as involved in the design of the study, data analysis, report writing, and manuscript preparation. AS was involved in the data analysis and review of the report. JS was involved in the design of the study and supervision of the research. All authors read and approved the final draft of the manuscript.

\section{Acknowledgments}

We acknowledge the faculty members from School of Nursing, Chitwan Medical College, Bharatpur, Chitwan, Nepal.

\section{References}

[1] A. F. Turkcapar, N. Kadığlu, E. Aslan, S. Tunc, M. Zayıfoğlu, and L. Mollamahmutoğlu, "Sociodemographic and clinical features of postpartum depression among Turkish women: a prospective study," BMC Pregnancy \& Childbirth, vol. 15, no. 1, p. 108, 2015.

[2] C. E. Parsons, K. S. Young, T. J. Rochat, M. L. Kringelbach, and A. Stein, "Postnatal depression and its effects on child development: a review of evidence from low- and middle-income countries," British Medical Bulletin, vol. 101, no. 1, pp. 5779, 2012.

[3] World Health Organization, Maternal mental health and child health and development in low and middle income countries: report of the meeting, World Health Organization, Geneva, Switzerland, 2008.

[4] American Psychiatric Association, Diagnostic and Statistical Manual of Mental Disorders (DSM- $5^{\circledR}$ ), American Psychiatric Publishing, 2013.

[5] J. L. Cox, J. M. Holden, and R. Sagovsky, "Detection of postnatal depression: development of the 10-item Edinburgh Postnatal Depression Scale," The British Journal of Psychiatry, vol. 150, no. 6, pp. 782-786, 1987.

[6] M. W. O'hara and A. M. Swain, "Rates and risk of postpartum depression-a meta-analysis," International Review of Psychiatry, vol. 8, no. 1, pp. 37-54, 1996.

[7] M. Chandran, P. Tharyan, J. Muliyil, and S. Abraham, "Postpartum depression in a cohort of women from a rural area of Tamil Nadu, India," The British Journal of Psychiatry, vol. 181, no. 6, pp. 499-504, 2002.

[8] R. K. Giri, R. B. Khatri, S. R. Mishra, V. Khanal, V. D. Sharma, and R. P. Gartoula, "Prevalence and factors associated with 
depressive symptoms among post-partum mothers in Nepal," BMC Research Notes, vol. 8, no. 1, p. 111, 2015.

[9] S. Regmi, W. Sligl, D. Carter, W. Grut, and M. Seear, "A controlled study of postpartum depression among Nepalese women: validation of the Edinburgh postpartum depression scale in Kathmandu," Tropical Medicine \& International Health, vol. 7, no. 4, pp. 378-382, 2002.

[10] D. Kunwar, E. Corey, P. Sharma, and A. Risal, "Screening for postpartum depression and associated factors among women who deliver at a university hospital, Nepal," Kathmandu University Medical Journal, vol. 13, no. 1, pp. 44-48, 2015.

[11] S. Shivalli and N. Gururaj, "Postnatal depression among rural women in South India: do socio-demographic, obstetric and pregnancy outcome have a role to play?," PLoS One, vol. 10, no. 4, article e0122079, 2015.

[12] M. M. T. Filha, S. Ayers, S. G. N. da Gama, and M. do Carmo Leal, "Factors associated with postpartum depressive symptomatology in Brazil: The Birth in Brazil National Research Study, 2011/2012," Journal of Affective Disorders, vol. 194, pp. 159-167, 2016.

[13] K. Clarke, N. Saville, B. Shrestha et al., "Predictors of psychological distress among postnatal mothers in rural Nepal: a cross-sectional community-based study," Journal of Affective Disorders, vol. 156, pp. 76-86, 2014.

[14] L. Murray, M. P. Dunne, T. Van Vo, P. N. T. Anh, N. G. Khawaja, and T. N. Cao, "Postnatal depressive symptoms amongst women in Central Vietnam: a cross-sectional study investigating prevalence and associations with social, cultural and infant factors," BMC Pregnancy and Childbirth, vol. 15, no. 1, p. 234, 2015.

[15] S. Dørheim Ho-Yen, G. Tschudi Bondevik, M. Eberhard-Gran, and B. Bjorvatn, "Factors associated with depressive symptoms among postnatal women in Nepal," Acta Obstetricia et Gynecologica Scandinavica, vol. 86, no. 3, pp. 291-297, 2007.

[16] N. R. Sabba, "Post partum depression among rajbansi women in Nepal," Researcher: A Research Journal of Culture and Society, vol. 1, no. 1, 2013.

[17] F. I. Al Hinai and S. S. Al Hinai, "Prospective study on prevalence and risk factors of postpartum depression in Al-dakhliya governorate in Oman," Oman Medical Journal, vol. 29, no. 3, pp. 198-202, 2014.

[18] N. D. Adama, P. Foumane, J. P. K. Olen, J. S. Dohbit, E. N. U. Meka, and E. Mboudou, "Prevalence and risk factors of postpartum depression in Yaounde, Cameroon," Open Journal of Obstetrics and Gynecology, vol. 5, no. 11, pp. 608-617, 2015. 